\title{
Determinants of arterial stiffness in COPD
}

\author{
Surya P Bhatt ${ }^{1{ }^{*}+}$, Adam G Cole ${ }^{1 \dagger}$, James Michael Wells ${ }^{1}$, Hrudaya Nath² ${ }^{2}$ Jubal R Watts ${ }^{2}$, John R Cockcroft ${ }^{3}$ \\ and Mark T Dransfield ${ }^{1,4}$
}

\begin{abstract}
Background: Cardiovascular morbidity and mortality is high in patients with chronic obstructive pulmonary disease (COPD) and arterial stiffness is a potentially modifiable risk factor with added predictive value beyond that obtained from traditional risk factors. Arterial stiffness has been the target of pharmacologic and exercise interventions in patients with COPD, but the effects appear limited to those patients with more significant elevations in arterial stiffness. We aimed to identify predictors of increased arterial stiffness in a cohort with moderate to severe COPD.
\end{abstract}

Methods: Aortic pulse wave velocity (aPWV) was measured in subjects with moderate to severe COPD enrolled in a multicenter randomized controlled trial. Subjects were categorized into quartiles based on aPWV values and factors affecting high arterial stiffness were assessed. Multivariate models were created to identify independent predictors of high aPWV, and cardiovascular disease (CVD).

Results: 153 patients were included. Mean age was 63.2 (SD 8.2) years and mean FEV 1 was 55.4 (SD 15.2) \% predicted. Compared to the quartile with the lowest aPWV, subjects in the highest quartile were older, had higher systolic blood pressure (SBP), were more likely to be current smokers, and had greater burden of thoracic aortic calcification. On multivariate analyses, age (adjusted OR $1.14,95 \% \mathrm{Cl} 1.05$ to $1.25, \mathrm{p}=0.003$ ) and SBP (adjusted OR $1.06,95 \% \mathrm{Cl} 1.02$ to $1.09, \mathrm{p}=0.001$ ) were independent predictors of elevated aPWV. Body mass index, therapy with cholesterol lowering medications and coronary calcification were independent predictors of CVD.

Conclusions: Elevated arterial stiffness in patients with COPD can be predicted using age, blood pressure and thoracic aortic calcification. This will help identify subjects for enrollment in clinical trials using aPWV for assessing the impact of COPD therapies on CV outcomes.

Trial registration: Clinicaltrials.gov NCT00857766

Keywords: COPD, Arterial stiffness, Arterial calcification, Cardiovascular

\section{Background}

Cardiovascular morbidity and mortality is high in patients with chronic obstructive pulmonary disease (COPD) and this appears to be independent of established risks such as smoking, gender and age [1-3]. A plausible mechanistic connection is the presence of chronic inflammation in both the lung and cardiovascular system $[1,4,5]$ which may be associated with endothelial dysfunction, $[4,6]$ loss of elastin, $[5,7,8]$ and eventual vascular calcification [9]. Though no disease specific marker of cardiovascular risk has been identified, many markers of this potentially shared pathophysiologic

\footnotetext{
* Correspondence: spbhatt@uab.edu

${ }^{\dagger}$ Equal contributors

'Lung Health Center, Division of Pulmonary, Allergy and Critical Care

Medicine, University of Alabama at Birmingham, Birmingham, AL 35294, USA

Full list of author information is available at the end of the article
}

process have been demonstrated to be present in patients with COPD including elevated c-reactive protein, $[1,2]$ arterial stiffness, $[5,7,10]$ and thoracic aortic calcification (TAC) [9] as well as impaired flow mediated vasodilation [6]. These associations are independent of smoking status, inversely related to lung function and directly related to the extent of emphysema as detected by quantitative CT scanning $[1,3,5,9]$.

Arterial stiffness is a potentially modifiable risk factor and has added predictive value beyond that obtained from traditional risk factors [11-13]. Arterial stiffness has been the target of pharmacologic and exercise interventions in patients with COPD [14-16]. Though these studies suggest a potential benefit with inhaled treatments and exercise, the effects with pharmacologic intervention appear limited to those patients with more 
significant elevations in arterial stiffness [14]. Identifying those subjects who are more likely to respond to interventions is of potential value in phenotyping and in targeting therapy. We aimed to identify predictors of increased arterial stiffness in a cohort with moderate to severe COPD.

\section{Methods}

\section{Study participants}

Subjects with moderate to severe COPD enrolled in a multicenter, randomized controlled study (NCT00857766) were included. Written informed consent was obtained from all participants, and the study was approved by the Institutional Review Board at the University of Alabama (IRB No. W110208001). Details of the study design have been published previously [14]. Briefly, we included patients age $\geq 50$ years and with at least 10 pack years smoking history with moderate to severe COPD as evidenced by a post-albuterol forced expiratory volume in the first second $\left(\mathrm{FEV}_{1}\right) /$ forced vital capacity $(\mathrm{FVC})$ ratio $\leq 0.70$, and $\mathrm{FEV}_{1}<80 \%$ predicted. Patients had to be on stable doses of medications for diabetes mellitus, hyperlipidemia and cardiovascular disease for at least 3 months prior to enrolment. Baseline demographic and clinical characteristics were used for all analyses. Cardiovascular disease included a history of coronary artery disease (angina, myocardial infarction, and ischemic heart disease without cardiomyopathy), cerebrovascular disease (stroke and transient ischemic attacks), or peripheral arterial disease.

\section{Blood, vascular and CT measurements}

Serum was obtained for measurement of lipids, blood glucose, and inflammatory markers (highly sensitive C-reactive protein, hs-CRP; and serum fibrinogen).

Aortic pulse wave velocity (aPWV) was measured using the SphygmoCor ${ }^{\mathrm{rm}}$ system (AtCorMedical, Sydney, Australia) by sequentially recording ECG-gated carotid and femoral artery waveforms by applanation tonometry. The distance between the site of measurement over the carotid and femoral arteries was divided by the wave transit time, averaged over ten cardiac cycles.

Multidetector computed tomography (CT) was used for quantitative estimation of emphysema. Scans were obtained at full inspiration $(120 \mathrm{kVp}, 100 \mathrm{mAs}$, slice thickness 1 or 1.25 - $\mathrm{mm}$ for 16 -slice scanners and 0.5 or $0.65 \mathrm{~mm}$ for 64 slice scanners). Percentage emphysema was calculated using the percentage of lung volume at total lung capacity with attenuation less than -950 Hounsfield Units (HU) using the Pulmonary Workstation 2.0 Software (VIDA Diagnostics, Coralville, IA, USA). Coronary artery calcification (CAC) and thoracic aortic calcification (TAC) were assessed using a postimaging processing application (Aquarius Work Station, TeraRecon, San Mateo, CA) using the Food and Drug
Administration-approved Calcium Analysis Tool. Coronary arterial calcification score was assessed by obtaining the sum of each CT slice's area of calcification multiplied by a coefficient based on the peak CT number (Agatston score). Areas of calcification were defined by the standard scoring threshold (>130 HU). Coronary arterial calcification was first scored using the semi-automated calcium analysis software and then manually corrected by a technologist when mischaracterized by the software algorithm. A radiologist ( $\mathrm{HN}$ or JW) then individually reviewed each case and additional corrections were made as needed. Thoracic aortic calcifications were scored separately using the same technique. Thoracic aorta was defined as the aorta, excluding brachiocephalic arteries, extending from aortic valve to the origin of the celiac axis.

\section{Statistical analyses}

Baseline data are expressed as means with standard deviations for normally distributed values. Bivariate analyses were conducted with chi-square test for categorical data and Student $\mathrm{t}$ test for continuous data where appropriate. CAC and TAC were $\log$ transformed as $C A C+1$ and TAC +1 . Associations with aPWV and clinical predictors were assessed using univariate and multivariate linear regression analyses. Subjects were then categorized into quartiles based on aPWV values, and comparisons were made between these groups using Analyses of Variance (ANOVA) and chi square tests as appropriate. Variables significant on univariate analyses were entered into a multinomial regression model with the lowest aPWV quartile as reference to find independent predictors of the highest aPWV. Subjects with and without CVD were compared, and predictors of CVD were assessed using logistic regression by including variables significant on univariate analyses. All analyses were performed with SPSS software (version 20.0) and a p value $<0.05$ was used to define statistical significance.

\section{Results}

Of the 249 patients enrolled in the clinical trial, 153 patients with complete CT data were included in the current analysis (Table 1). Mean age was 63.2 (SD 8.2) years. Patients were predominantly Caucasian (92\%) and there was an almost equal sex distribution (54\% males). Approximately half of the patients were active smokers. Of the 153 patients, 101 had moderate COPD as defined by the Global Initiative for Chronic Obstructive Lung Disease (GOLD COPD stage II) and 52 had severe COPD (GOLD stage III-IV) [17]. Patients with GOLD stage III/IV had a lower body mass index than those with GOLD stage II and as expected, also had greater \% emphysema on CT. There was a modest correlation between pulse pressure and aPWV (Pearson's $r=0.36$, 
Table 1 Demographics of patients with COPD

\begin{tabular}{|c|c|c|c|c|}
\hline & All subjects ( $n=153$ ) & GOLD II $(n=101)$ & GOLD III/IV (n=52) & $p$ value \\
\hline Age (years) & $63.2(8.2)$ & $63.4(8.7)$ & $63.1(7.2)$ & 0.86 \\
\hline Male, n (\%) & $83(55 \%)$ & $56(56 \%)$ & $27(52 \%)$ & 0.63 \\
\hline Race, Caucasian, n (\%) & $140(92 \%)$ & $92(91 \%)$ & $49(94 \%)$ & 0.67 \\
\hline $\mathrm{BMI}\left(\mathrm{kg} / \mathrm{m}^{2}\right)$ & $26.9(4.8)$ & $27.6(4.7)$ & $25.5(4.7)$ & 0.01 \\
\hline Current smoker, n (\%) & $77(49 \%)$ & $50(50 \%)$ & $25(48 \%)$ & 0.82 \\
\hline Total pack-years & $56.5(29.4)$ & $56.2(27)$ & $57.1(33.8)$ & 0.87 \\
\hline $\mathrm{FEV}_{1}$ (\% predicted) & $55.4(15.2)$ & $64.8(7.5)$ & $37.4(8.4)$ & $<0.001$ \\
\hline $\mathrm{FEV}_{1}(\mathrm{~L})$ & $1.62(0.6)$ & $1.9(0.52)$ & $1.08(0.29)$ & $<0.001$ \\
\hline $\mathrm{FEV}_{1} / \mathrm{FVC}$ & $0.55(0.11)$ & $0.59(0.08)$ & $0.53(0.09)$ & $<0.001$ \\
\hline Coronary artery disease, n (\%) & $46(30 \%)$ & $32(32 \%)$ & $14(27 \%)$ & 0.52 \\
\hline Diabetes mellitus,n (\%) & $45(30 \%)$ & $30(30 \%)$ & $15(29 \%)$ & 0.88 \\
\hline Cerebrovascular disease, n (\%) & $6(4 \%)$ & $5(5 \%)$ & $1(2 \%)$ & 0.67 \\
\hline Peripheral vascular disease, n (\%) & $13(9 \%)$ & $11(11 \%)$ & $2(4 \%)$ & 0.22 \\
\hline Cardiovascular disease, n (\%) & $53(35 \%)$ & $39(39 \%)$ & $14(27 \%)$ & 0.16 \\
\hline Systolic BP & $127.6(17.1)$ & $128.8(17)$ & $125.3(17.3)$ & 0.24 \\
\hline Temperature $\left({ }^{\circ} \mathrm{C}\right)$ & $36.5(0.3)$ & $36.5(0.3)$ & $36.5(0.4)$ & 0.50 \\
\hline TAC & $3556.8(6156.9)$ & $3923.2(7919.4)$ & $2852.0(3616.1)$ & 0.31 \\
\hline CAC & $741.2(1061.4)$ & $789.6(1094.9)$ & $648.1(997.3)$ & 0.44 \\
\hline $\mathrm{aPW}(\mathrm{m} / \mathrm{s})$ & $9.98(2.85)$ & $10.14(2.88)$ & $9.69(2.79)$ & 0.37 \\
\hline \% CT emphysema & $8.93(11.39)$ & $5.63(7.32)$ & $15.28(14.76)$ & $<0.001$ \\
\hline Total cholesterol (mmol/L) & $4.81(1.1)$ & $4.73(1.12)$ & $4.94(1.04)$ & 0.24 \\
\hline LDL cholesterol (mmol/L) & $2.59(0.97)$ & $2.53(0.92)$ & $2.71(1.07)$ & 0.28 \\
\hline HDL cholesterol (mmol/L) & $1.45(0.53)$ & $1.38(0.49)$ & $1.59(0.58)$ & 0.03 \\
\hline hsCRP (mg/L) & $4.59(7.0)$ & $5.05(8.16)$ & $3.70(3.73)$ & 0.27 \\
\hline Plasma glucose (mmol/L) & $5.85(1.4)$ & $6.05(1.53)$ & $5.44(0.95)$ & 0.01 \\
\hline
\end{tabular}

All values expressed as mean (standard deviation) unless otherwise specified.

$P$ value for comparisons between GOLD II and GOLD III/IV.

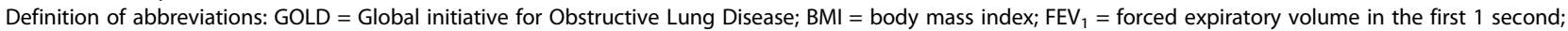

$\mathrm{FVC}=$ forced vital capacity; TAC = thoracic aortic calcification; $\mathrm{CAC}=$ coronary arterial calcification; $\mathrm{aPWV}=$ aortic pulse wave velocity; $\mathrm{CT}=$ computed

tomography; $\mathrm{LDL}=$ low density lipoprotein; $\mathrm{HDL}=$ high density lipoprotein; $\mathrm{hsCRP}=$ high sensitivity $\mathrm{C}$-reactive protein.

$\mathrm{p}<0.01)$. Figure 1 shows the distribution of aPWV by GOLD COPD stage.

Univariate analysis revealed significant associations between aPWV and multiple risk factors such as age (unstandardized beta co-efficient, $ß=0.13$, 95\% CI 0.08 to $0.18 ; \mathrm{p}<0.001)$, number of pack-years of smoking ( $\beta=0.02$, $95 \%$ CI 0.003 to $0.03 ; \mathrm{p}=0.02)$, systolic blood pressure $(\beta=0.06,95 \%$ CI 0.03 to $0.08 ; \mathrm{p}<0.001)$, temperature $(\beta=1.4,95 \% \mathrm{CI} 0.06$ to $2.75 ; \mathrm{p}=0.04)$, plasma glucose $(\beta=0.37,95 \%$ CI 0.05 to $0.69 ; \mathrm{p}=$ $0.02), \log C A C(\beta=0.19,95 \%$ CI 0.02 to $0.36 ; p=0.03)$, $\log \mathrm{TAC}(\beta=0.41,95 \% \mathrm{CI} 0.2$ to $0.62 ; \mathrm{p}<0.001)$, and $\mathrm{CVD}$ $((\beta=1.05,95 \% \mathrm{CI} 0.11$ to $1.99 ; \mathrm{p}=0.03)$. LDL-cholesterol $(ß=-0.16,95 \% \mathrm{CI}=-0.63$ to $0.31 ; \mathrm{p}=0.51)$ and treatment with lipid lowering medications $(\beta=0.87,95 \% \mathrm{CI}=-0.04$ to $1.19 ; \mathrm{p}=0.06$ ) were not associated with aPWV. There was no association between aPWV and markers of inflammation, C-reactive protein $(B=0.06,95 \%$ CI -0.01 to $0.12 ; \mathrm{p}=0.08)$ and fibrinogen $(\beta=-0.01,95 \% \mathrm{CI}-0.63$ to $0.61 ; \mathrm{p}=0.96)$, or with diabetes mellitus $(\beta=0.93,95 \%$ $\mathrm{CI}=-0.05$ to $1.91 ; \mathrm{p}=0.06)$. There was also no association between \%emphysema on $\mathrm{CT}$ scan and aPWV $(~(B=0.03,95 \% \mathrm{CI}-0.01$ to $0.07 ; \mathrm{p}=0.17)$ though a relationship was observed when log \%emphysema was used $(ß=0.33,95 \%$ CI 0.01 to $0.64 ; \mathrm{p}=0.04)$. On multivariate analyses, there was a significant association between aPWV and age, glucose, temperature and systolic blood pressure (Table 2).

Subjects were divided into four quartiles based on percentile aPWV (Table 3). On comparison with the quartile with the lowest aPWV, subjects in the highest quartile were older $(68.1+8.4$ vs. $59.4+7.2$ years, $\mathrm{p}<0.01)$, had higher systolic blood pressure $(134.7+16.8$ vs. $120.5+17.3 \mathrm{mmHg}, \mathrm{p}<0.01)$, and had greater burden of thoracic aortic calcification $(\log$ TAC $7.64+1.31$ vs. $6.28+2.16, \mathrm{p}<0.01$ ) (Table 3). They were also more 


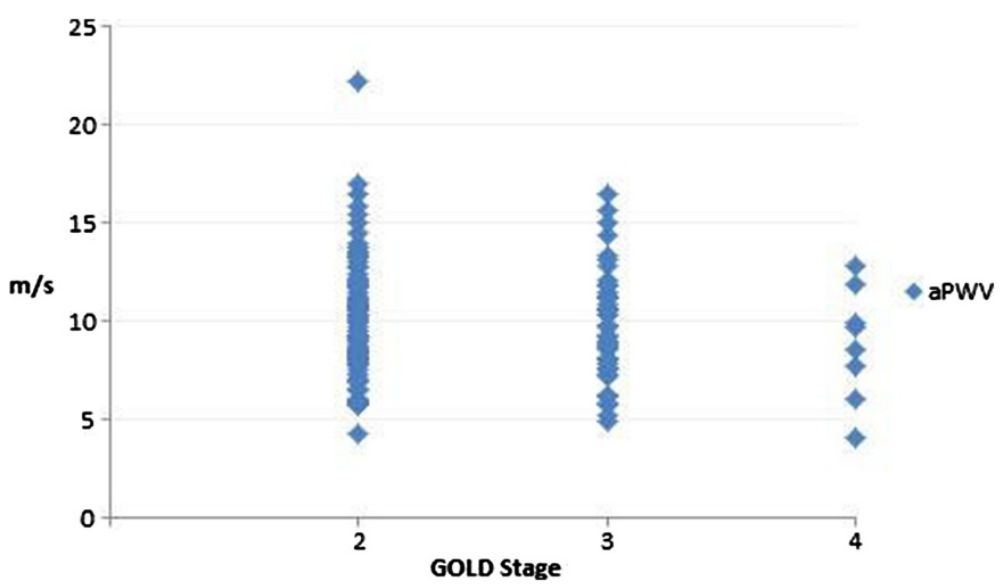

Figure 1 Distribution of aortic pulse wave velocity (aPWV) by GOLD stage.

likely to be current smokers ( $68 \%$ vs. $34 \%, \mathrm{p}<0.05)$. Subjects in the highest quartile had a greater frequency of CVD, but this was not entered in the multivariate model as this was an outcome of interest (Table 3). On multivariate analyses, subjects in the highest aPWV quartile were older (adjusted odds ratio, OR 1.14, 95\% CI 1.05 to $1.25, \mathrm{p}=0.003)$, and had greater systolic blood pressure (adjusted OR 1.06, 95\% CI 1.02 to $1.09, \mathrm{p}=0.001$ ). LogTAC did not reach statistical significance (adjusted $\mathrm{OR}=1.14,95 \%$ CI 0.82 to $1.58, \mathrm{p}=0.44$ ).

We also assessed predictors of prevalent CVD and found that BMI, markers of dyslipidemia, cholesterol lowering medications, coronary calcification and aPWV were significantly associated with CVD on univariate analyses (Table 4). On multivariate analyses, BMI, cholesterol lowering medications and $\log C A C$ were independent predictors of CVD. aPWV was not independently associated with CVD on multivariate testing $(\mathrm{p}=0.06)($ Table 4$)$.

\section{Discussion}

We have shown that in patients with moderate to severe COPD, arterial stiffness can be predicted by older age, higher systolic blood pressure and greater thoracic aortic calcification. These factors could be used to select patients for clinical trials aimed at modifying aPWV as a surrogate for CVD risk.

A large proportion of patients with COPD die from cardiovascular causes rather than from respiratory failure, especially in mild to moderate disease, and this appears to be independent of traditional risk factors for CVD [18]. Efforts to uncover novel prognostic markers have led to the identification of coronary and aortic calcification, and arterial stiffness as predictors of incident coronary artery disease $[13,19]$. These markers are indicative of vascular and target organ damage and add to the predictive utility of traditional risks [20-22]. Patients in the current study had a significant burden of traditional cardiovascular risk factors. We confirmed that despite this, CAC and aPWV proved to be robust predictors of CVD in COPD. This has been demonstrated in other special populations including, the very elderly and in those with other systemic and inflammatory diseases $[12,23,24]$. There was an inverse relationship between dyslipidemia and CVD, an effect likely explained by treatment as subjects with CVD were more likely to be on statins and cholesterol lowering medications than those without CVD $(62 \%$ vs. $33 \%, \mathrm{p}<0.001)$. The intake of cholesterol lowering medications was independently associated with CVD.

While arterial calcification is a robust predictor of CVD, it is probably not modifiable. aPWV is the gold standard for measuring arterial stiffness and population based studies have shown that it is an independent risk factor for cardiovascular disease [25-27]. Multiple studies in the general population have shown that arterial stiffness can be modified by intervention $[28,29]$.

Table 2 Multivariate associations between clinical variables and aortic pulse wave velocity

\begin{tabular}{lcc}
\hline & $\begin{array}{c}\text { Regression co-efficient beta } \\
\mathbf{9 5 \%} \text { confidence interval) }\end{array}$ & p value \\
\hline Age & $0.1(0.04-0.17)$ & 0.001 \\
$\begin{array}{l}\text { Systolic blood } \\
\text { pressure }(\mathrm{mmHg})\end{array}$ & $0.04(0.02-0.07)$ & 0.001 \\
Temperature $\left({ }^{\circ} \mathrm{C}\right)$ & $1.17(0.534-3.02)$ & 0.006 \\
Plasma glucose $(\mathrm{mmol} / \mathrm{L})$ & $0.47(0.15-0.78)$ & 0.004 \\
Pack-years & $0.012(-0.002-0.027)$ & 0.09 \\
Cardiovascular disease & $0.90(-0.029-1.829)$ & 0.06 \\
logTAC & $0.18(-0.12-0.47)$ & 0.24 \\
logCAC & $-0.23(-0.50-0.03)$ & 0.08 \\
\hline
\end{tabular}

Definition of abbreviations: TAC Thoracic Aortic Calcification. CAC Coronary Artery Calcification.

Adjusted $\mathrm{R}^{2}=0.29$. 
Table 3 Comparison of variables across aPWV quartiles

\begin{tabular}{|c|c|c|c|c|}
\hline & $\begin{array}{l}\text { Quartile } 1(4.1-8.04 \mathrm{~m} / \mathrm{s}) \\
\mathrm{n}=38\end{array}$ & $\begin{array}{l}\text { Quartile } 2(8.05-9.69 \mathrm{~m} / \mathrm{s}) \\
\mathrm{n}=36\end{array}$ & $\begin{array}{l}\text { Quartile } 3(9.7-11.74 \mathrm{~m} / \mathrm{s}) \\
\mathrm{n}=41\end{array}$ & $\begin{array}{l}\text { Quartile } 4(>11.75 \mathrm{~m} / \mathrm{s}) \\
\mathrm{n}=38\end{array}$ \\
\hline Age (years) $¥$ & $59.4(7.2)$ & $61.7(6.9)$ & $63.6(7.7)^{*}$ & $68.1(8.4)^{* *}$ \\
\hline Male, n (\%) & $20(53)$ & $17(47)$ & $22(54)$ & $24(63)$ \\
\hline Race, Caucasian, n (\%) & $34(89)$ & $33(92)$ & $39(95)$ & $36(95)$ \\
\hline $\mathrm{BMI}\left(\mathrm{kg} / \mathrm{m}^{2}\right)$ & $26.4(4.8)$ & $27.2(4.9)$ & $26.1(4.6)$ & $28.0(4.7)$ \\
\hline Current smoker, n (\%) & $13(34)$ & $18(50)$ & $20(49)$ & $26(68)^{*}$ \\
\hline Total pack-years & $55.32(29.81)$ & $48.75(23.67)$ & $55.56(20.59)$ & $66.92(38.69)$ \\
\hline FEV 1 (\%predicted) & $52.99(15.17)$ & $59.56(13.43)$ & $55.18(15.36)$ & $54.26(15.97)$ \\
\hline $\mathrm{FEV}_{1}(\mathrm{~L})$ & $1.61(0.62)$ & $1.76(0.62)$ & $1.60(0.58)$ & $1.54(0.57)$ \\
\hline Cardiovascular disease, n (\%) & $10(26)$ & $8(22)$ & $14(34)$ & $21(55)^{*}$ \\
\hline Diabetes mellitus, n (\%) & $8(21)$ & $11(31)$ & $10(24)$ & $17(45)$ \\
\hline Heart Rate (per minute) & $69.6(10.3)$ & $69.1(11.1)$ & $68.5(13.4)$ & $71.2(8.8)$ \\
\hline $\begin{array}{l}\text { Systolic blood pressure } \\
(\mathrm{mmHg}) ¥\end{array}$ & $120.5(17.3)$ & $125.9(14.1)$ & $128.8(17.2)^{*}$ & $134.7(16.8)^{* *}$ \\
\hline $\begin{array}{l}\text { Diastolic blood pressure } \\
(\mathrm{mmHg})\end{array}$ & $75.9(10.1)$ & $78.1(11.1)$ & $75.7(8.3)$ & $78.6(9.3)$ \\
\hline $\log T A C$ & $6.28(2.16)$ & $6.17(2.17)$ & $7.20(1.97)^{*}$ & $7.64(1.31)^{* *}$ \\
\hline $\log C A C$ & $5.43(1.80)$ & $5.10(2.44)$ & $5.71(1.97)$ & $5.66(2.05)$ \\
\hline $\mathrm{aPW}(\mathrm{m} / \mathrm{s})$ & $6.7(1.1)$ & $8.8(0.4)$ & $10.6(0.5)$ & $13.7(2.1)$ \\
\hline \%emphysema on CT & $7.2(9.1)$ & $6.6(9.3)$ & $11.1(14.1)$ & $10.3(11.7)$ \\
\hline LDL cholesterol (mmol/L) & $2.56(1.04)$ & $2.66(0.98)$ & $2.61(0.93)$ & $2.60(1.03)$ \\
\hline $\mathrm{HDL}$ cholesterol (mmol/L) & $1.42(0.53)$ & $1.51(0.68)$ & $1.52(0.47)$ & $1.35(0.41)$ \\
\hline Total cholesterol (mmol/L) & $4.75(0.97)$ & $4.86(1.10)$ & $4.93(1.18)$ & $4.70(1.16)$ \\
\hline Log hsCRP (mg/L) & $0.95(0.88)$ & $0.76(0.95)$ & $1.08(1.02)$ & $1.28(1.12)$ \\
\hline Log fibrinogen (mg/dl) & $1.10(0.21)$ & $0.98(0.28)^{*}$ & $1.07(0.29)$ & $1.08(0.20)$ \\
\hline
\end{tabular}

${ }^{*} \mathrm{p}<0.05$. ${ }^{* *} \mathrm{p}<0.01$ for quartiles compared with quartile 1 .

$¥ p<0.01$ on multivariate analyses for quartile 4 compared with quartile 1 .

All values expressed as mean (standard deviation) unless otherwise specified.

Definition of abbreviations: $B M I$ body mass index, $F E V_{1}$ forced expiratory volume in the first 1 second, TAC thoracic aortic calcification, $C A C$ coronary arterial calcification, $a P W V$ aortic pulse wave velocity, $C T$ computed tomography, $L D L$ low density lipoprotein, $H D L$ high density lipoprotein, $h s C R P$ high sensitivity C-reactive protein.

Because aPWV is a dynamic measurement and is possibly a precursor to CVD, there has also been interest in the use of aPWV as a surrogate endpoint in clinical trials examining the effects of COPD therapies on cardiovascular morbidity and mortality [14,15]. Vivodtzev et al. showed that a 4 week endurance training program resulted in significant improvement in arterial stiffness in subjects with COPD [16]. This was confirmed by Gale et al. who found that pulmonary rehabilitation positively impacts arterial stiffness [30]. In both these

Table 4 Unadjusted and adjusted odds ratios for predictors of cardiovascular disease

\begin{tabular}{lcc}
\hline & Unadjusted odds ratio $(\mathbf{9 5} \%$ confidence interval) & Adjusted odds ratio (95\% confidence interval) \\
\hline Body mass index $\left(\mathrm{kg} / \mathrm{m}^{2}\right)$ & $1.11(1.03-1.19)^{* *}$ & $1.12(1.01-1.21)^{*}$ \\
High density lipoprotein $(\mathrm{mmol} / \mathrm{L})$ & $0.32(0.14-0.72)^{* *}$ & - \\
Low density lipoprotein $(\mathrm{mmol} / \mathrm{L})$ & $0.53(0.36-0.78)^{* *}$ & - \\
Total cholesterol $(\mathrm{mmol} / \mathrm{L})$ & $0.53(0.37-0.75)^{* *}$ & $1.40(1.11-1.76)^{* *}$ \\
logCAC & $1.43(1.16-1.76)^{* *}$ & $0.30(0.12-0.71)^{* *}$ \\
Cholesterol lowering medications & $0.30(0.15-0.61)^{* *}$ & $3.02(0.94-9.77)$ \\
\hline
\end{tabular}

${ }^{*} \mathrm{p}<0.05 .{ }^{* *} \mathrm{p}<0.01$.

$\mathrm{CAC}=$ Coronary artery calcification. $\mathrm{aPWV}=$ Aortic pulse wave velocity. 
studies, the major effector of this reduction appeared to be a reduction in blood pressure. On the other hand, we and others have shown previously that inhaled corticosteroid/long acting beta agonist likely reduces arterial stiffness, and this reduction is greatest in those with the highest stiffness $[14,15]$. Whether this is due to reduction in inflammation is unclear. Sabit et al. found a positive correlation between serum interleukin- 6 and arterial stiffness in COPD, [10] but in another study there was no relation between $\mathrm{C}$-reactive protein and arterial stiffness [5]. In the current study we also found no significant associations between markers of systemic inflammation and arterial stiffness. Beta agonists may also reduce arterial stiffness via nitric oxide synthesis and vasodilation [31]. In this study, in addition to age and blood pressure, we showed that thoracic arterial calcification can also be used to predict arterial stiffness. Interestingly, there was no association between severity of emphysema and arterial stiffness, unlike seen in a previous study [5]. It is not clear if this variance in COPD related arterial stiffness is due to differences in emphysema severity or involvement of other mechanisms that were not assessed. We did find a significant relationship between log CT emphysema and aPWV suggesting that the non-normal distribution of emphysema in this population may in part explain the lack of linear correlation.

This study has some limitations. CT scans included in this study were not EKG-gated; however, a recent study showed that non-gated computed tomography is reliable for estimation of TAC and CAC [32]. In addition, the study only included patients with COPD, precluding comparisons of strengths of association in matched controls. However, we did stratify arterial stiffness to determine contributing factors.

\section{Conclusions}

In summary, this study demonstrates that in patients with COPD elevated arterial stiffness can be predicted using age, blood pressure and thoracic aortic calcification. This will help identify subjects for enrollment in clinical trials using aPWV for assessing the impact of COPD therapies on $\mathrm{CV}$ outcomes. In addition, the findings suggest that aPWV may be an important predictor of CVD in subjects with COPD.

\section{Competing interests}

S P B, A G C, J M W, H N, and J R W report no conflicts of interest. J R C received a research grant from GlaxoSmithKline to do this study. M T D reports consultant fees and speaker fees from GlaxoSmithKline and Boerhinger Ingelheim. The authors declare that they have no competing interests.

\section{Authors' contributions}

SPB and AGC contributed equally to writing the manuscript. SPB and MTD analyzed the data. HN and JRW measured arterial calcification, and reviewed the manuscript for important intellectual content. JMW and JRC reviewed the manuscript for important intellectual content. MTD conceptualized the study, contributed to writing the manuscript and reviewed the manuscript for important intellectual content. MTD is the guarantor of the contents of this manuscript. All authors approved the final version of this manuscript.

\section{Funding}

GlaxoSmithKline, Respiratory and Immuno-Inflammation Medicines Development Center, Research Triangle Park, NC, USA

\section{Author details}

${ }^{1}$ Lung Health Center, Division of Pulmonary, Allergy and Critical Care Medicine, University of Alabama at Birmingham, Birmingham, AL 35294, USA. ${ }^{2}$ Department of Radiology, University of Alabama at Birmingham,

Birmingham, AL, USA. ${ }^{3}$ Department of Cardiology, Wales Heart Research Institute, University Hospital, Cardiff, UK. ${ }^{4}$ The Birmingham VA Medical Center, Birmingham, AL, USA.

Received: 7 July 2013 Accepted: 31 December 2013

Published: 4 January 2014

\section{References}

1. Sin DD, Wu L, Man SF: The relationship between reduced lung function and cardiovascular mortality: a population-based study and a systematic review of the literature. Chest 2005, 127(6):1952-1959.

2. Sin DD, Man SF: Why are patients with chronic obstructive pulmonary disease at increased risk of cardiovascular diseases? The potential role of systemic inflammation in chronic obstructive pulmonary disease. Circulation 2003, 107(11):1514-1519.

3. Barr RG, Ahmed FS, Carr JJ, Hoffman EA, Jiang R, Kawut SM, Watson K: Subclinical atherosclerosis, airflow obstruction and emphysema: the MESA lung study. Eur Respir J 2012, 39(4):846-854.

4. Coulson JM, Rudd JH, Duckers JM, Rees JI, Shale DJ, Bolton CE, Cockcroft JR: Excessive aortic inflammation in chronic obstructive pulmonary disease: an 18 F-FDG PET pilot study. J Nucl Med 2010, 51(9):1357-1360.

5. McAllister DA, Maclay JD, Mills NL, Mair G, Miller J, Anderson D, Newby DE, Murchison JT, Macnee W: Arterial stiffness is independently associated with emphysema severity in patients with chronic obstructive pulmonary disease. Am J Respir Crit Care Med 2007, 176(12):1208-1214.

6. Barr RG, Mesia-Vela S, Austin JH, Basner RC, Keller BM, Reeves AP, Shimbo D, Stevenson L: Impaired flow-mediated dilation is associated with low pulmonary function and emphysema in ex-smokers: the emphysema and cancer action project (EMCAP) study. Am J Respir Crit Care Med 2007, 176(12):1200-1207.

7. Mills NL, Miller JJ, Anand A, Robinson SD, Frazer GA, Anderson D, Breen L, Wilkinson IB, McEniery CM, Donaldson K, et al: Increased arterial stiffness in patients with chronic obstructive pulmonary disease: a mechanism for increased cardiovascular risk. Thorax 2008, 63(4):306-311.

8. Maclay JD, McAllister DA, Rabinovich R, Haq I, Maxwell S, Hartland S, Connell M, Murchison JT, van Beek EJ, Gray RD, et al: Systemic elastin degradation in chronic obstructive pulmonary disease. Thorax 2012, 67(7):606-612.

9. Dransfield MT, Huang F, Nath H, Singh SP, Bailey WC, Washko GR: $\mathrm{CT}$ emphysema predicts thoracic aortic calcification in smokers with and without COPD. COPD 2010, 7(6):404-410.

10. Sabit R, Bolton CE, Edwards PH, Pettit RJ, Evans WD, McEniery CM, Wilkinson IB, Cockcroft JR, Shale DJ: Arterial stiffness and osteoporosis in chronic obstructive pulmonary disease. Am J Respir Crit Care Med 2007, 175(12):1259-1265.

11. Yeboah J, McClelland RL, Polonsky TS, Burke GL, Sibley CT, O'Leary D, Carr JJ, Goff DC, Greenland P, Herrington DM: Comparison of novel risk markers for improvement in cardiovascular risk assessment in intermediate-risk individuals. JAMA 2012, 308(8):788-795.

12. Kawai VK, Solus JF, Oeser A, Rho YH, Raggi P, Bian A, Gebretsadik T, Shintani A, Stein CM: Novel cardiovascular risk prediction models in patients with systemic lupus erythematosus. Lupus 2011, 20(14):1526-1534.

13. van Popele NM, Grobbee DE, Bots ML, Asmar R, Topouchian J, Reneman RS, Hoeks AP, van der Kuip DA, Hofman A, Witteman JC: Association between arterial stiffness and atherosclerosis: the rotterdam study. Stroke 2001, 32(2):454-460.

14. Dransfield MT, Cockcroft JR, Townsend RR, Coxson HO, Sharma SS, Rubin DB, Emmett AH, Cicale MJ, Crater GD, Martinez FJ: Effect of fluticasone propionate/salmeterol on arterial stiffness in patients with COPD. Respir Med 2011, 105(9):1322-1330. 
15. Sabit RBC, Allanby C, Cockcroft JR, Shale DJ: Arterial stiffness is reduced by combination inhaled corticosteroid/long acting beta-2 agonist therapy in patients with COPD. Volume 62Thorax; 2007:A142

16. Vivodtzev I, Minet C, Wuyam B, Borel JC, Vottero G, Monneret D, Baguet JP, Levy $P$, Pepin JL: Significant improvement in arterial stiffness after endurance training in patients with COPD. Chest 2010, 137(3):585-592.

17. Pauwels RA, Buist AS, Calverley PM, Jenkins CR, Hurd SS: Global strategy for the diagnosis, management, and prevention of chronic obstructive pulmonary disease. NHLBI/WHO global initiative for chronic obstructive lung disease (GOLD) workshop summary. Am J Respir Crit Care Med 2001, 163(5):1256-1276.

18. Zielinski J, MacNee W, Wedzicha J, Ambrosino N, Braghiroli A, Dolensky J, Howard P, Gorzelak K, Lahdensuo A, Strom K, et al: Causes of death in patients with COPD and chronic respiratory failure. Monaldi Arch Chest Dis 1997, 52(1):43-47.

19. Arad Y, Goodman KJ, Roth M, Newstein D, Guerci AD: Coronary calcification, coronary disease risk factors, C-reactive protein, and atherosclerotic cardiovascular disease events: the St. Francis heart study. J Am Coll Cardiol 2005, 46(1):158-165.

20. Kavousi M, Elias-Smale S, Rutten JH, Leening MJ, Vliegenthart R, Verwoert GC, Krestin GP, Oudkerk M, de Maat MP, Leebeek FW, et al: Evaluation of newer risk markers for coronary heart disease risk classification: a cohort study. Ann Intern Med 2012, 156(6):438-444.

21. Budoff MJ, Nasir K, Katz R, Takasu J, Carr JJ, Wong ND, Allison M, Lima JA, Detrano R, Blumenthal RS, et al: Thoracic aortic calcification and coronary heart disease events: the multi-ethnic study of atherosclerosis (MESA). Atherosclerosis 2011, 215(1):196-202.

22. Mattace-Raso FU, van der Cammen TJ, Hofman A, van Popele NM, Bos ML, Schalekamp MA, Asmar R, Reneman RS, Hoeks AP, Breteler MM, et al: Arterial stiffness and risk of coronary heart disease and stroke: the rotterdam study. Circulation 2006, 113(5):657-663.

23. Tota-Maharaj R, Blaha MJ, McEvoy JW, Blumenthal RS, Muse ED, Budoff MJ, Shaw LJ, Berman DS, Rana JS, Rumberger J, et al: Coronary artery calcium for the prediction of mortality in young adults $<45$ years old and elderly adults $>75$ years old. Eur Heart J 2012, 33(23):2955-2962.

24. Matsuoka M, Iseki K, Tamashiro M, Fujimoto N, Higa N, Touma T, Takishita S: Impact of high coronary artery calcification score (CACS) on survival in patients on chronic hemodialysis. Clin Exp Nephrol 2004, 8(1):54-58.

25. Laurent S, Boutouyrie P, Asmar R, Gautier I, Laloux B, Guize L, Ducimetiere P, Benetos A: Aortic stiffness is an independent predictor of all-cause and cardiovascular mortality in hypertensive patients. Hypertension 2001, 37(5):1236-1241.

26. Vlachopoulos C, Aznaouridis K, Stefanadis C: Prediction of cardiovascular events and all-cause mortality with arterial stiffness: a systematic review and meta-analysis. J Am Coll Cardiol 2010, 55(13):1318-1327.

27. Willum-Hansen T, Staessen JA, Torp-Pedersen C, Rasmussen S, Thijs L, Ibsen H, Jeppesen J: Prognostic value of aortic pulse wave velocity as index of arterial stiffness in the general population. Circulation 2006, 113(5):664-670.

28. Seals DR, Tanaka H, Clevenger CM, Monahan KD, Reiling MJ, Hiatt WR, Davy KP, DeSouza CA: Blood pressure reductions with exercise and sodium restriction in postmenopausal women with elevated systolic pressure: role of arterial stiffness. J Am Coll Cardiol 2001, 38(2):506-513.

29. Vaitkevicius PV, Fleg JL, Engel JH, O'Connor FC, Wright JG, Lakatta LE, Yin FC, Lakatta EG: Effects of age and aerobic capacity on arterial stiffness in healthy adults. Circulation 1993, 88(4 Pt 1):1456-1462.

30. Gale NS, Duckers JM, Enright S, Cockcroft JR, Shale DJ, Bolton CE: Does pulmonary rehabilitation address cardiovascular risk factors in patients with COPD? BMC Pulm Med 2011, 11:20

31. Dawes M, Chowienczyk PJ, Ritter JM: Effects of inhibition of the L-arginine/nitric oxide pathway on vasodilation caused by betaadrenergic agonists in human forearm. Circulation 1997, 95(9):2293-2297.

32. Budoff MJ, Nasir K, Kinney GL, Hokanson JE, Barr RG, Steiner R, Nath H, Lopez-Garcia C, Black-Shinn J, Casaburi R: Coronary artery and thoracic calcium on noncontrast thoracic CT scans: comparison of ungated and gated examinations in patients from the COPD gene cohort. J Cardiovasc Comput Tomogr 2011, 5(2):113-118.

doi:10.1186/1471-2466-14-1

Cite this article as: Bhatt et al:: Determinants of arterial stiffness in COPD. BMC Pulmonary Medicine 2014 14:1.

\section{Submit your next manuscript to BioMed Central and take full advantage of:}

- Convenient online submission

- Thorough peer review

- No space constraints or color figure charges

- Immediate publication on acceptance

- Inclusion in PubMed, CAS, Scopus and Google Scholar

- Research which is freely available for redistribution 